Ouwehand, C., Ridder, D.T.D. de, Bensing, J.M. Individual differences in the use of proactive coping strategies by middle-aged and older adults. Personality and Individual Differences: 2008, 45(1), 28-33

\begin{tabular}{|l|l|}
\hline Postprint Version & 1.0 \\
\hline Journal website & $\underline{\text { http://dx.doi.org/10.1016/j.paid.2008.02.013 }}$ \\
\hline Pubmed link & \\
\hline DOI & $10.1016 /$ j.paid.2008.02.013 \\
\hline
\end{tabular}

This is a NIVEL certified Post Print, more info at http://www.nivel.eu

\title{
Individual differences in the use of proactive coping strategies by middle-aged and older adults
}

\author{
CAROLIJN OUWEHAND, DENISE T.D. DE RIDDER AND JOZIEN M. BENSING
}

Department of Clinical and Health Psychology, Utrecht University, P.O. Box 80.140, 3508 TC Utrecht, The Netherlands

\begin{abstract}
The concept of proactive coping refers to the process of screening one's environment for future stressors and undertaking attempts to prevent them. As of yet, few empirical studies have been conducted in relation to this promising concept. The aim of the present study was to identify the personal characteristics that contribute to the engagement in proactive coping with potential changes in three important life domains, namely health, social relationships and personal finance. We collected data in a sample of adults aged 50-70 ( $\mathrm{N}=123)$ regarding proactive coping and five trait variables, namely future temporal orientation, goal orientation, dispositional optimism, self-efficacy, and aging anxiety. Results showed that future temporal orientation and, to a lesser extent, goal orientation were significantly associated with proactive coping. In addition, a higher educational level was also important for explaining individual differences in proactive coping, but not regarding all types of potential changes. It seems that the impact of trait factors on proactive coping partially depends on the type of future stressor that is encountered and the skills that are necessary to deal with it effectively.
\end{abstract}

\section{INTRODUCTION}

The ability to cope with stressful changes is considered to be an important ingredient for successful development in adulthood, since it may contribute to individuals' continuing to strive for and achieve valued personal goals, thus leading to a higher level of subjective wellbeing ([Brunstein, 1993], [Diener et al., 1999] and [Rapkin and Fischer, 1992]). Coping strategies have mainly been researched from a reactive point of view, through studies which examine the way people respond to stressors that pose a threat to personal goals once they have occurred. It is equally important, however, to study individuals' ability to recognize future threats and to use strategies that may help to offset these problems at an early stage, that is, whether they can engage in proactive coping ([Aspinwall, 1997], [Aspinwall, 2005] and [Aspinwall and Taylor, 1997]). So far, few empirical studies relating to the concept of proactive coping have been conducted. Nevertheless, the idea that people are not doomed to passively wait for things to happen, but that they are able to look forward and take appropriate measures in order to prevent or diminish a probable threat or its adverse outcomes is appealing and warrants empirical examination (see also [Gan et al., 2007] and 
Ouwehand, C., Ridder, D.T.D. de, Bensing, J.M. Individual differences in the use of proactive coping strategies by middle-aged and older adults. Personality and Individual Differences: 2008, 45(1), 28-33

[Schwarzer and Taubert, 2002]). Middle-aged and older adults seem to be a suitable population in which to examine these processes, since this age group faces the task of adapting to potential threats associated with aging, such as changes in personal health, friendships, and finances. The aim of the present study is to examine individual differences in proactive coping in people aged 50-70.

In this paper, proactive coping is defined as the processes which are employed to detect and prevent probable goal threats while working towards personal goals (Aspinwall, 1997). According to this conception, future stressors are by definition only potentially threatening and, as such, they remain more or less ambiguous. Consequently, they must be monitored over time in order to determine whether the potential threats develop into real problems (Aspinwall, 1997). Not surprisingly, Aspinwall and Taylor (1997) regard avoiding the possible obstacle as an ineffective strategy: if an individual disengages from a potential threat, he or she is not able to take appropriate measures to offset the stressor at the right moment. Active, problem-focused and support-seeking strategies are necessary to deal effectively with a future stressor and its consequences. In addition, problem-focused coping increases the chance that the individual will be supplied with valuable information about the development of the threat as well as the effect of the initial coping attempts to change the course of the stressor (Aspinwall \& Taylor, 1997).

This study focuses on proactive coping with potential, stressful changes in three different life domains, namely health, social relationships, and personal finance. Previous research by the authors has demonstrated that being healthy, having good social relationships, and having sufficient financial resources were most important for middle-aged and older adults aged 50-70 (Ouwehand, De Ridder, \& Bensing, 2001). They considered a negative change in these domains as a serious threat to their goals. We developed three vignettes (for details, see Ouwehand, De Ridder, \& Bensing, 2006) each describing a situation in which an individual faces a probable, but uncertain change associated with aging, in accordance with Aspinwall and Taylor's definition about what proactive coping entails.

An interesting question is to what extent individual differences in proactive coping can be explained by personality traits. A first candidate is future temporal orientation, which can be described as a concern for the future, and the ability to plan and to imagine future possibilities (Jones, Banicky, Lasane, \& Pomare, 2005). It has been suggested that future temporal orientation may assist in the detection of a potential stressor (Aspinwall \& Taylor, 1997) as well as the engagement in preventive behavior (Rothspan \& Read, 1996). Goal orientation (Malouff et al., 1990) is another personality trait expected to facilitate proactive coping, since people who have the tendency to set both short-term and long-term goals may be better able to recognize potential stressors that threaten these goals. Furthermore, previous research has demonstrated that dispositional optimism, i.e. people who hold positive beliefs about their future (Scheier, Carver, \& Bridges, 1994), pay more attention to information that informs them about an upcoming negative event ([Aspinwall and Brunhart, 1996] and [Aspinwall and Brunhart, 2000]). The employment of proactive coping strategies may also be facilitated by self-efficacy, because people with higher self-efficacy perceive threats as less stressful (Jerusalem, 1993), which may encourage them to use proactive coping, since individuals who perceive themselves being at lower risk pay more attention to future threats (Aspinwall \& Brunhart, 1996). Finally, individuals who are more anxious about the aging process may be more occupied with future stressors associated with aging and, therefore, they may naturally show a higher tendency to attending and dealing with stressors to their concern.

To summarize, the aim of this article is to examine to what extent five personality traits are related to the employment of proactive coping with three future stressors associated with aging. For this purpose, middle-aged and older adults aged 50-70 are asked to respond to three different vignettes that each represent a potential, negative change in their lives, namely a decline in health, a negative change in social contacts, and a decrease in financial 
Ouwehand, C., Ridder, D.T.D. de, Bensing, J.M. Individual differences in the use of proactive coping strategies by middle-aged and older adults. Personality and Individual Differences: 2008, 45(1), 28-33

resources. It is hypothesized that each of the personality traits will show a positive association with proactive coping.

\section{METHOD}

\subsection{Participants and procedure}

The present study is a follow-up study of a larger survey-study $(N=397)$ examining proactive coping employed by normal, healthy middle-aged and older adults aged between 50 and 70 years old. It consisted of 123 adults (63 men and 60 women) with a mean age of $61.8(S D=5.0)$ who were willing to participate in an interview. Of this smaller sample, $10 \%$ reported primary school as their highest completed education, 30\% had a high school diploma, 36\% had finished vocational training, and $24 \%$ had a college or university degree. With regard to marital status, $72 \%$ were married, $7 \%$ were divorced and $11 \%$ were widowed while $10 \%$ had never been married. Finally, $28 \%$ of the participants were in paid employment, $38 \%$ were retired and $7 \%$ were declared partially disabled. Only $2 \%$ were searching for a job while the remaining $25 \%$ reported housekeeping as their main activity. No significant differences were found between the original sample and the present sample with respect to age and gender, although participants in the current study had a slightly higher level of education $(t=3.0, p<.001)$.

Participants were interviewed at the university or at home when there were mobility problems. After an appointment had been made by telephone, they received a short questionnaire which they filled in at home and which they brought to the interview. The questionnaire assessed several personality traits. During the interview, participants were asked to respond to three vignettes in order to measure proactive coping in three different situations.

\subsection{Proactive coping}

The method used to measure proactive coping has been reported in detail elsewhere (see Ouwehand et al., 2006). Three vignettes were developed which each described a potential stressful change in one of three major life domains, namely health (situation 1), social relationships (situation 2), and personal finance (situation 3). Research has shown that vignettes are a valid method for triggering coping responses so long as certain conditions are met: (1) individuals have the opportunity to process the information adequately in a quiet environment without distraction (Stolte, 1994); (2) the situations described in the vignettes are imaginable; and (3) the vignettes cause a certain amount of threat (Krohne \& Egloff, 1999). Therefore, care was taken that participants were interviewed in a quiet room in order to allow them to concentrate and process the information effectively. Moreover, previous research has shown that most people were familiar with the situations described in the vignettes and that they could imagine them very well. In addition, it demonstrated that all situations were regarded as moderately threatening (Ouwehand et al., 2006).

After reading the vignette carefully, participants were asked to indicate how they would respond to the potential stressor. Effective proactive coping consists of various strategies, such as planning, seeking instrumental support and preventing a potential stressor instead of denying the problem and disengaging from it. In order to measure these strategies, we asked them to respond to 16 items on a four-point Likert scale. These items were derived from four COPE scales (Carver, Scheier, \& Weintraub, 1989), namely active coping, planning, suppression of competing activities, and seeking support for instrumental reasons, that each consisted of four items. Some of these items were changed slightly in order to make them more appropriate for a proactive coping context (see Ouwehand et al., 2006). For the purpose of this article, three proactive coping sum scores were computed, one for each situation. Internal consistency was high: Cronbach's $\alpha=.88, .92$ and .90 for the health vignette, social contacts vignette and finance vignette respectively. 
Ouwehand, C., Ridder, D.T.D. de, Bensing, J.M. Individual differences in the use of proactive coping strategies by middle-aged and older adults. Personality and Individual Differences: 2008, 45(1), 28-33

\subsection{Individual characteristics}

Besides three sociodemographic variables (age, gender and educational level), five personality traits, namely future temporal orientation, goal orientation, dispositional optimism, self-efficacy, and aging anxiety were included in this study. Future temporal orientation was measured with the future subscale of the Temporal Orientation Scale (Jones et al., 2005). Participants had to answer 5 items on a five-point Likert scale (Cronbach's $\alpha=.61)$. Sample items are "I take care of what needs to be done before having fun" and "I am able to resist temptation when there is work to be done". A high score means that a person is a planner, is concerned with the future, and is able to imagine future possibilities.

In addition, participants completed the Goal Orientation Scale developed by Malouff et al. (1990) in order to assess goal orientation, that is the degree to which an individual has a tendency to set short-term as well as long-term goals and make plans to achieve these goals. It consists of 15 items on a five-point Likert scale (Cronbach's $\alpha=.72$ ) and sample items include "I am goal-oriented" and "I spend a substantial amount of time planning how to reach my goals".

Dispositional optimism was measured with the Revised Life Orientation Test (LOT-R) developed by Scheier et al. (1994). It consists of 6 items on a five-point Likert scale (Cronbach's $\alpha=.73$ ). A sum score was computed with a higher score indicating a higher tendency to believe that one will generally experience good outcomes in life.

We used the Generalized Self-Efficacy Scale (Schwarzer, 1992) to assess self-efficacy, which may be defined as the belief that one is capable of coping with difficulties and that one's own actions are responsible for success. The scale consists of 10 items on a four-point Likert scale (Cronbach's $\alpha=.84$ ). Sample items are "I can usually handle whatever comes my way" and "I can always manage to solve difficult problems if I try hard enough".

Finally, the Aging Anxiety Scale (Lynch, 2000) was used to assess aging anxiety. This scale consists of seven items on a five-point Likert scale (Cronbach's $\alpha=.66$ ) and includes items, such as "The older I become, the more anxious I am about the future" and "I worry that people will have to make decisions for me when I am older". A higher score indicates that an individual is more occupied with aging and has more concerns or fears about getting older.

\subsection{Data analyses}

To examine the associations between proactive coping in the three situations (health, social contacts and personal finance) and the scores on the self-report scales that assessed the personality traits, Pearson correlation coefficients were calculated. In addition, the relative contribution of the significant trait variables of the correlation analysis was examined by adding them as independent variables in three separate linear regression models with the three proactive coping scores as dependent variables.

\section{RESULTS}

Table 1 displays the means and standard deviations of proactive coping in the three different situations. One-way analysis of variance demonstrated a significant difference in the employment of proactive coping strategies $(F(2,364)=4.75, p<.01)$. Post-hoc analyses showed that participants reported using more proactive coping in the health situation than in the social contacts situation $(p=.01)$. In addition, a trend was found for the difference between the finance situation and the social contacts situation $(p=.10)$. Table 2 shows that the individual characteristics correlated slightly to moderately with each other. Since all correlations were below .90 and collinearity diagnostics showed that the VIF-values of the individual variables were far below 10.0 (range $=1.1-1.6$ ), they were regarded as being sufficiently independent of each other, so we decided to include all variables in subsequent analyses. 
Ouwehand, C., Ridder, D.T.D. de, Bensing, J.M. Individual differences in the use of proactive coping strategies by middle-aged and older adults. Personality and Individual Differences: 2008, 45(1), 28-33

\section{[TABLE 1]}

\section{[TABLE 2.]}

As can be seen in Table 3, none of the sociodemographic variables showed a significant association with proactive coping regarding a potential, negative change in social contacts whereas education was significantly and positively correlated with proactive coping with a future decline in health and financial resources. In addition, men tend to use more proactive coping regarding financial matters than women. Of the five individual characteristics, only future temporal orientation and goal orientation demonstrated significant, positive correlations with proactive coping in all three situations. None of the other personality traits were found to be significantly related to proactive coping.

\section{[TABLE 3]}

Linear regression analyses (see Table 4) demonstrated that individual differences in proactive coping were significantly associated with future temporal orientation. People who were more concerned with the future undertook more actions in order to attempt to prevent potential negative changes in health, social relationships, and financial resources. Interestingly, the relative contribution of educational level was even more important, but only for proactive coping with health and proactive coping with personal finance. It was not significantly associated with proactive coping regarding social contacts. Finally, individual differences in proactive coping with a potential decline in health were significantly related to goal orientation. The linear regression models explained $18 \%$ of the total variance of proactive coping with health, $7 \%$ of proactive coping with social contacts and $23 \%$ of proactive coping with finances.

\section{[TABLE 4.]}

\section{DISCUSSION}

The aim of the present study was to examine individual differences in the use of proactive coping strategies, i.e. the strategies people employ to prevent future stressors (Aspinwall, 1997), by middle-aged and older adults aged $50-70$. This is an interesting age group in which to examine proactive coping, since it is likely to be confronted with many potential future changes due to aging. We confronted the adults with three ecologically relevant issues, namely a potential decline in health, a potential change in social contacts, and a potential decrease in financial resources. We examined to what extent differences in proactive coping with these situations were associated with five personality traits, namely future temporal orientation, goal orientation, dispositional optimism, self-efficacy, and aging anxiety.

A robust finding was demonstrated for future temporal orientation. It appeared to be an important variable for explaining differences in proactive coping in all situations. As predicted, people who had the tendency to be a planner and to be concerned about their future undertook more efforts to prevent potential stressful changes in health, social relationships and personal finance. The importance of being future oriented for proactive coping has been suggested by other authors ([Aspinwall and Taylor, 1997] and [Rothspan and Read, 1996]), but the present study is one of the first studies that confirm this hypothesis.

In addition, the results indicated that goal orientation was also significantly associated with individual differences in proactive coping in all three situations. People who had a tendency to think about their short-term and long-term goals used more proactive coping in order to prevent future threats to these goals. However, the regression models showed that its relative influence was less important than future temporal orientation, except for differences in 
Ouwehand, C., Ridder, D.T.D. de, Bensing, J.M. Individual differences in the use of proactive coping strategies by middle-aged and older adults. Personality and Individual Differences: 2008, 45(1), 28-33

proactive coping with a potential decline in health. Health can be considered as one of the most important resources for self-regulation, especially in older age. Preserving good health is often not an ultimate goal in itself, but a prerequisite to maintaining and pursuing numerous different types of personal goals that contribute to subjective well-being. Therefore, it seems logical that people who were more goal-oriented make more efforts to prevent a future decrease in one of the most important resources that may help them to achieve their goals, namely good health.

Regarding the three sociodemographic variables included in this study (age, gender and education) interesting results were found. It appeared that individual differences in proactive coping were associated with differences in educational level, but that this result was not found for all types of potential stressors. People who had a higher level of education employed more proactive coping strategies in order to prevent negative changes regarding their health and personal finance, but not regarding their social contacts. Gender was also important for proactive coping with financial matters; men used more proactive coping strategies than women. However, the effect of gender disappeared when education was entered into the model, which may be explained by the fact that, in this age cohort, gender was strongly correlated with educational level with men generally having completed a higher level of education than women.

The finding that education is important for the use of proactive coping is consistent with the few studies that have researched the association between education and future planning and prevention ([Pill et al., 1995] and [Prenda and Lachman, 2001]). This result may be explained by the idea that, through education, people gain several skills that are important for effectively engaging in the proactive coping process. These skills include problemsolving and analytic skills as well as communication skills. Having learned these skills may generate a sense of personal control (Ross \& Wu, 1995) as well as knowledge about how to deal with difficult situations.

Current findings demonstrated that proactive coping was not related to optimism, selfefficacy, and aging anxiety. A possible explanation may be that the middle-aged and older adults in our study were on average moderately to highly optimistic, had moderate to high self-efficacy and were not very anxious about the aging process, which may have made them a rather homogenous sample. Other personal features not included in this study may also explain additional variance in proactive coping. For example, in the case of a potential negative change in social relationships, it is possible that proactive coping in this situation may depend more on factors such as differences in network size and need for social contacts than on stable personality characteristics.

Interestingly, the results of this study seem to suggest that whether or not individual differences in proactive coping are explained by certain trait factors is also a question of the type of future stressor that is confronted. Some personal characteristics, such as having a future temporal orientation and, to a lesser extent, being goal-oriented, may under all circumstances be essential for engaging in proactive coping. However, it is likely that other personal features, such as education, only contribute to proactive coping when certain types of potential stressors are confronted. Depending on the skills that are necessary to manage that particular stressor effectively, a personality trait may or may not explain individual differences in proactive coping regarding a potential threat. Previous research has already demonstrated that not all present or future stressors are confronted in the same way (e.g. [De Ridder and Kerssens, 2003], [Ouwehand et al., 2006] and [Stewart and Schwarzer, 1996]). For future research, it would be interesting to examine this stressor-dependent relationship between personality traits and proactive coping more closely.

A limitation of this study may be the potential artificiality of vignettes that may have weaken the external validity of the results (De Ridder \& Kerssens, 2003); the responses given to the vignettes may not be perfectly similar to the responses that would have been given in real life situations. Nevertheless, previous results have shown that most people were familiar with the situations described in the vignettes that were used in this study (Ouwehand 
Ouwehand, C., Ridder, D.T.D. de, Bensing, J.M. Individual differences in the use of proactive coping strategies by middle-aged and older adults. Personality and Individual Differences: 2008, 45(1), 28-33

et al., 2006). Moreover, several people reported that they had already experienced the same or a comparable situation, which may have led to even more accurate responses of proactive coping, since they could imagine the situation well.

Another limitation is that the personality variables did not explain much of the variance in proactive coping, especially in the case of the confrontation with a probable future decline in social contacts. Again, it seems that proactive coping in this situation is more dependent of other variables than the personality variables included in this study.

To summarize, the present study demonstrated that future temporal orientation and, to a lesser extent, goal orientation are important trait factors in predicting the extent to which people engage in the proactive coping process in order to prevent future stressors. People who are more inclined to make plans for the future and to see future possibilities and who have the tendency to set goals for themselves use more proactive coping strategies.

Interestingly, the study also showed that the relationship between personality traits and proactive coping may partially depend on the type of potential stressor that is encountered.

\section{REFERENCES}

Aspinwall, 1997 L.G. Aspinwall, Where planning meets coping: Proactive coping and the detection and management of potential stressors. In: S.L. Friedman and E.K. Scholnick, Editors, The developmental psychology of planning: Why, how, and when do we plan?, Lawrence Erlbaum Associates, London (1997), pp. 285-320.

Aspinwall, 2005 L.G. Aspinwall, The psychology of future-oriented thinking: From achievement to proactive coping, adaptation, and aging, Motivation and Emotion 29 (2005), pp. 203-235.

Aspinwall and Brunhart, 1996 L.G. Aspinwall and S.M. Brunhart, Distinguishing optimism from denial: Optimistic beliefs predict attention to health threats, Personality and Social Psychology Bulletin 22 (1996), pp. 993-1003.

Aspinwall and Brunhart, 2000 L.G. Aspinwall and S.M. Brunhart, What I do know won't hurt me: Optimism, attention to negative information, coping, and health. In: J.E. Gillham, Editor, The science of optimism and hope: Research essays in honor of Martin E.P. Seligman, PA: Templeton Foundation Press, West Conshohocken (2000), pp. 163-200.

Aspinwall and Taylor, 1997 L.G. Aspinwall and S.E. Taylor, A stitch in time: Self-regulation and proactive coping, Psychological Bulletin 121 (1997), pp. 417-436.

Brunstein, 1993 J.C. Brunstein, Personal goals and subjective well-being: A longitudinal study, Journal of Personality and Social Psychology 65 (1993), pp. 1061-1070.

Carver et al., 1989 C.S. Carver, M.F. Scheier and J.K. Weintraub, Assessing coping strategies: A theoretically based approach, Journal of Personality and Social Psychology 56 (1989), pp. 267-283.

De Ridder and Kerssens, 2003 D.T.D. De Ridder and J. Kerssens, Owing to the force of circumstances? The impact of situational features and personal characteristics on coping patterns across situations, Psychology and Health 18 (2003), pp. 217-236.

Diener et al., 1999 E. Diener, E.M. Suh, R.E. Lucas and H.L. Smith, Subjective well-being: Three decades of progress, Psychological Bulletin 125 (1999), pp. 276-302.

Gan et al., 2007 Y. Gan, M. Yang, Y. Zhou and Y. Zhang, The two-factor structure of futureoriented coping and its mediating role in student engagement, Personality and Individual Differences 43 (2007), pp. 851-863.

Jerusalem, $1993 \mathrm{M}$. Jerusalem, Personal resources, environmental constraints, and adaptational processes: The predictive power of a theoretical stress model, Personality and Individual Differences 14 (1993), pp. 15-24.

Jones et al., 2005 Jones, J. M., Banicky, L., Lasane, T. P., \& Pomare, M. (2005). A temporal orientation scale: Focusing attention on past, present and future. Unpublished manuscript, University of Delaware.

Krohne and Egloff, 1999 H.W. Krohne and B. Egloff, Vigilant and avoidant coping: Theory and measurement. In: C.D. Spielberger and I.G. Sarason, Editors, Stress and emotion Vol. 17, Taylor \& Francis, Washington DC (1999).

Lynch, 2000 S.M. Lynch, Measurement and prediction of aging anxiety, Research on Aging 22 (2000), pp. 533-558. 
Ouwehand, C., Ridder, D.T.D. de, Bensing, J.M. Individual differences in the use of proactive coping strategies by middle-aged and older adults. Personality and Individual Differences:

2008, 45(1), 28-33

Malouff et al., 1990 J. Malouff, N. Schutte, M. Bauer, D. Mantelli, B. Pierce and G. Cordova et al., Development and evaluation of a measure of the tendency to be goal oriented, Personality and Individual Differences 11 (1990), pp. 1191-1200.

Ouwehand and De Ridder, 2001 Ouwehand, C., De Ridder, D. T. D., \& Bensing, J. M. (2001). Proactive adaptation to ageing: An exploratory focus group study. Unpublished manuscript.

Ouwehand et al., 2006 C. Ouwehand, D.T.D. De Ridder and J.M. Bensing, Situational aspects are more important in shaping proactive coping behaviour than individual characteristics: A vignette study among adults preparing for ageing, Psychology and Health 21 (2006), pp. 809-825.

Pill et al., 1995 R. Pill, T.J. Peters and M.R. Robling, Social class and preventive health behaviour: A British example, Journal of Epidemiology and Community Health 49 (1995), pp. 28-32.

Prenda and Lachman, 2001 K.M. Prenda and M.E. Lachman, Planning for the future: A life management strategy for increasing control and life satisfaction in adulthood, Psychology and Aging 16 (2001), pp. 206-216.

Rapkin and Fischer, 1992 B.D. Rapkin and K. Fischer, Framing the construct of life satisfaction in terms of older adults' personal goals, Psychology and Aging 7 (1992), pp. 138-149.

Ross and Wu, 1995 C.E. Ross and C. Wu, The links between education and health, American Sociological Review 60 (1995), pp. 719-745.

Rothspan and Read, 1996 S. Rothspan and S.J. Read, Present versus future time perspective and HIV risk among heterosexual college students, Health Psychology 15 (1996), pp. 131-134.

Scheier et al., 1994 M.F. Scheier, C.S. Carver and M.W. Bridges, Distinguishing optimism from neuroticism (and trait anxiety, self-mastery, and self-esteem): A reevaluation of the Life Orientation Test, Journal of Personality and Social Psychology 67 (1994), pp. 10631078.

Schwarzer, 1992 R. Schwarzer, Self-efficacy: Thought control of action, Hemisphere, Washington DC (1992).

Schwarzer and Taubert, 2002 R. Schwarzer and S. Taubert, Tenacious goal pursuits and striving toward personal growth: Proactive coping. In: E. Frydenberg, Editor, Beyond coping: Meeting goals, visions and challenges, Oxford University Press, London (2002), pp. 19-35.

Stewart and Schwarzer, 1996 S.M. Stewart and R. Schwarzer, Stability of coping in Hong Kong medical students: A longitudinal study, Personality and Individual Differences 20 (1996), pp. 245-255.

Stolte, 1994 J.F. Stolte, The context of satisficing in vignette research, Journal of Social Psychology 134 (1994), pp. 727-733.

\section{TABLES}


Ouwehand, C., Ridder, D.T.D. de, Bensing, J.M. Individual differences in the use of proactive coping strategies by middle-aged and older adults. Personality and Individual Differences:

Table 1

Means $(M)$ and standard deviations $(S D)$ of proactive coping in three different situations and the individual characteristics $(N=123)$

\begin{tabular}{|l|l|l|l|}
\hline & Possible range & $M$ & $S D$ \\
\hline Proactive coping - health & $16-64$ & 44.8 & 9.7 \\
\hline Proactive coping - social contacts & $16-64$ & 40.7 & 11.5 \\
\hline Proactive coping - finance & $16-64$ & 43.6 & 10.6 \\
\hline Future temporal orientation & $5-25$ & 17.0 & 3.2 \\
\hline Goal orientation & $15-75$ & 39.6 & 7.3 \\
\hline Dispositional optimism & $6-30$ & 23.1 & 4.4 \\
\hline Self-efficacy & $10-40$ & 33.2 & 4.3 \\
\hline Aging anxiety & $7-35$ & 16.8 & 5.2 \\
\hline
\end{tabular}

Table 2

Zero-order Pearson correlations between the individual characteristics $(N=123)$

\begin{tabular}{|l|l|l|l|l|l|l|l|}
\hline & $\mathbf{1}$ & $\mathbf{2}$ & $\mathbf{3}$ & $\mathbf{4}$ & $\mathbf{5}$ & $\mathbf{6}$ & $\mathbf{7}$ \\
\hline 1. Age & - & & & & & & \\
\hline 2. Gender & .01 & - & & & & & \\
\hline 3. Education & -.10 & $.45^{*}$ & - & & & & \\
\hline 4. Future orientation & -.17 & .02 & -.06 & - & & & \\
\hline 5. Goal orientation & $-.22^{*}$ & .12 & .11 & $.46^{*}$ & - & & \\
\hline $\begin{array}{l}\text { 6. Dispositional } \\
\text { optimism }\end{array}$ & $.19^{*}$ & .01 & .01 & -.01 & -.14 & - & \\
\hline 7. Self-efficacy & -.12 & .13 & -.09 & $.22^{*}$ & .14 & $.19^{*}$ & - \\
\hline 8. Aging anxiety & -.18 & -.06 & -.02 & .16 & $* 25^{*}$ & $* .53^{*}$ & $*-.25^{*}$ \\
\hline
\end{tabular}

Notes: Gender: 1 = female, 2 = male.

$p<.05$.

$* * p<.01$. 
Ouwehand, C., Ridder, D.T.D. de, Bensing, J.M. Individual differences in the use of proactive coping strategies by middle-aged and older adults. Personality and Individual Differences: 2008, 45(1), 28-33

\section{Table 3}

Zero-order Pearson correlation between the individual characteristics and proactive coping in three life domains $(N=123)$

\begin{tabular}{|l|l|l|l|}
\hline & PC - health & PC - social contacts & PC - finance \\
\hline PC - health & - & & \\
\hline PC - social contacts & $.51^{* *}$ & - & \\
\hline PC - finance & $.40^{* *}$ & $.42^{* *}$ & - \\
\hline & & & \\
\hline Age & -.07 & .01 & -.08 \\
\hline Gender & .12 & .04 & $.25^{* *}$ \\
\hline Education & $.22^{* *}$ & .01 & $.34^{* *}$ \\
\hline & & & \\
\hline Future temporal orientation & $.28^{* *}$ & $.23^{* *}$ & $.29^{* *}$ \\
\hline Goal orientation & $.31^{* *}$ & $.21^{*}$ & $.18^{*}$ \\
\hline Dispositional optimism & .01 & .09 & .00 \\
\hline Self-efficacy & .10 & -.01 & -.03 \\
\hline Aging anxiety & .11 & -.02 & .04 \\
\hline
\end{tabular}

Notes: $\mathrm{PC}=$ proactive coping; gender: $1=$ female, $2=$ male.

$p<.05$.

$* * p<.01$ 
Ouwehand, C., Ridder, D.T.D. de, Bensing, J.M. Individual differences in the use of proactive coping strategies by middle-aged and older adults. Personality and Individual Differences: 2008, 45(1), 28-33

Table 4

Linear regression analyses for variables predicting proactive coping in three life domains

\begin{tabular}{|c|c|c|c|c|c|c|c|c|c|c|c|c|}
\hline \multirow[b]{2}{*}{ Variable } & \multicolumn{4}{|c|}{ PC-health } & \multicolumn{4}{|c|}{ PC-social contacts } & \multicolumn{4}{|c|}{ PC-finance } \\
\hline & $B$ & $\underset{B}{\mathrm{SE}}$ & $\beta$ & $t$ & $B$ & $\underset{B}{\mathrm{SE}}$ & $\beta$ & $t$ & B & $\underset{B}{\mathrm{SE}}$ & $\beta$ & $t$ \\
\hline \multicolumn{13}{|c|}{$\mathrm{PC}$ - health; $\mathrm{PC}-$ social contacts; $\mathrm{PC}$ - finance } \\
\hline Gender & & & & & & & & & 2.52 & 1.94 & .12 & 1.30 \\
\hline Education & .97 & .36 & .23 & 270 & & & & & 1.45 & .42 & .32 & 340 \\
\hline $\begin{array}{l}\text { Future } \\
\text { temporal } \\
\text { orientation }\end{array}$ & .57 & .29 & .18 & * 1.97 & .82 & .31 & .23 & $2.60^{*}$ & 1.00 & .31 & .30 & $\% 23$ \\
\hline $\begin{array}{l}\text { Goal } \\
\text { orientation }\end{array}$ & .27 & .13 & .21 & $\hbar^{2.16}$ & .22 & .16 & .14 & 1.41 & -.03 & .14 & -.02 & -.23 \\
\hline $\begin{array}{l}F \text {-value } \\
\text { regression } \\
\text { model }\end{array}$ & \multicolumn{4}{|c|}{$\begin{array}{l}F(3,117)=7.97 \\
p<.001\end{array}$} & \multicolumn{4}{|c|}{$F(2,118)=4.16, p=.02$} & \multicolumn{4}{|c|}{$F(4,114)=8.39, p<.001$} \\
\hline$R^{2}$ & \multicolumn{4}{|c|}{$18 \%$} & \multicolumn{4}{|l|}{$7 \%$} & \multicolumn{4}{|l|}{$23 \%$} \\
\hline
\end{tabular}

Notes: $\mathrm{PC}=$ proactive coping; gender: $1=$ female, $2=$ male.

$p<.05$

*** $p<.01$. 